BIJDRAGEN TOT DE KENNIS DER FAUNA VAN CURAÇAO.

Resultaten eener Reis van Dr. C. J. VAN DER HORST in 1920.

\title{
RHIZOCEPHALA OF CURAÇAO
}

\author{
BY \\ H. BOSCHMA \\ Zoological Laboratory of the University of Leiden.
}

(With five text figures and one plate).

The authors who have studied the Rhizocephala have a quite different opinion as to the limits of the species, especially those of the genus Sacculina. On the one side Kossmann (1874) and GIARD $(1887,1888)$ are convinced that every specimen of Sacculina found on a certain crab has to be separated specifically from those living on another host. On the other hand SMITH (1906) unites all the described species of Sacculina into one widely distributed species which has to keep the name Sacculina carcini. A better way in separating the forms of Sacculina into different species is without doubt the one avoiding both the extremes of the above-cited authors, as explained by GUERINGaNivet (1911). Only in the cases where morphological structures of specific value are found the forms are to be regarded as different species. A more detailed account of the questions dealing with the difficulties of the species-problem in Sacculina will be published in the monograph on the Rhizocephala of the Siboga Expedition, now in preparation by Professor VAN KAMPEN and the present author. Here only may be pointed to some particularities found in the material dealt with in this paper.

The material collected by Dr. VAN DER HORST at Curaçao contains four specimens of Rhizocephalid parasites. Three of these belong to the genus Sacculina, the fourth is a representative of the genus Lernaeodiscus. All of these differ from the hitherto known species of the two genera and are therefore described as new species in this paper. Though the material is comparatively small it is of great interest since the three species of Sacculina have a quite different structure. In this paper the structure of the external cuticle is used as a base in the diagnosis of the species. Many species of Sacculina, especially those from tropical regions, possess appendages on this chitinous cuticle, which have in a certain specimen a well-defined form. The size of the appendages may be different in the various regions of the mantle (e.g. those in the neighbourhood of the stalk may be of smaller size than those next to the mantle-opening), but within certain limits the form of these appendages is constant. Already Kossmann (1874) made use of the appendages of the external cuticle in the diagnosis of his species, but most authors have not employed this method. Some years ago VAN KAMPEN (1919), however, pointed out that the principles of Kossmans's method could give good results in the taxonomy of this group.

The appendages of the external cuticle of the mantle in the three species of Sacculina described in the following pages are highly different, and these characteristics probably will already furnish sufficient data for an identification of the species. The study of the internal organs revealed that also in this way each of the species is at first sight to be distinguished from the others and from Sacculina carcini, the species in which the internal anatomy is fully known by the researches of DeLAGE (1884). For more particulars I refer to the description of the internal organs of each of the species in the following pages. 
The new species of Lernaeodiscus, L. bilobatus, is easily to be distinguished from the other species of this genus by the presence of the two accessory mesenteries. In this genus the external cuticle of the mantle gives no clue for distinguishing characteristics of the different species.

I have cut off a small portion of the mantle of each of the specimens for the study of wholly mounted fragments of its cuticular layers. From the remainder of the body series of sections were made, those of Sacculina in longitudinal direction, that of Lernaeodiscus in a transversal direction. The sections were stained with aluminous carmine, some of the preparations of the mantle with haematoxylin. As for the species of Sacculina in the descriptions of the internal organs I have used the terms "anterior, posterior, dorsal, and ventral" in the same sense as SMITH (1906). In the case of Lernaeodiscus I have used the orientation which has been accepted by the same author in a later paper (SMITH, 1915). In the description of the external form of the parasites the terms breadth, height, and thickness have been used in another sense: the space between the laterally compressed surfaces is called the thickness, the greatest dimension the breadth, and the height is measured from the stalk to the mantle-opening.

\title{
Sacculina hirsuta n. sp.
}

\author{
(P1. II, figs. 1 and 5, text fig. 1).
}

Caracas Bay, Curaçao, 19. IV. 1920, 1 ex. on Pilumnus caribaeus Desb. \& Schr. ㅇ.

The parasite, which has a laterally compressed oval shape, is attached with a short stalk to the abdomen of its host. Its dimensions are: breadth 5 , height $31 / 2$, and thickness $2 \mathrm{~mm}$. The entire surface is provided with grooves which are deeper in the marginal parts and shallower in the central part of each lateral surface. The mantle-opening is situated at the top of a small papilla, the sides of which also possess some furrows. This papilla is found at the surface which is directed towards the thorax of the crab, near the free edge. The surface of the parasite which touched the abdomen of the crab is deeply hollowed out by the pressure of the surroundings of the gut of the crab.

The mantle possesses well-developed muscles and contains a great number of lacunes. Its

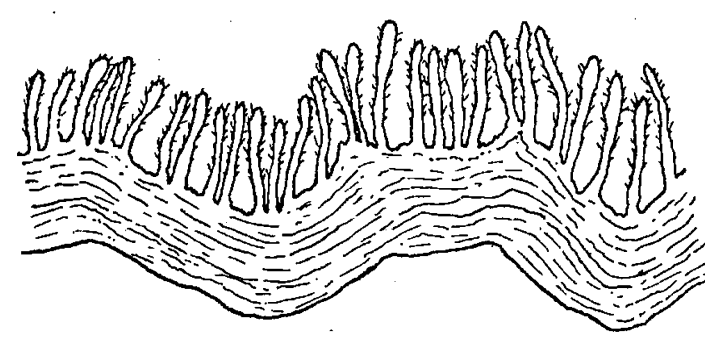

Fig. 1. Sacculina hirsuta. Section of the external cuticle of the mantle. $\times 370$. external surface is covered by a comparatively thick cuticle (fig. 1), which measures from $12 \mu$ in the neighbourhood of the stalk to about $30 \mu$ in the parts which surround the mantle-opening. This cuticle consists of layers of chitin which are directed parallel with the surface of the mantle. The free surface of the external cuticle is covered with hair-like appendages which can attain in the region near the mantle-opening a length of $35 \mu$. Towards the peduncle the hairs gradually become much shorter. Each of these appendages has a blunt, more or less rounded free extremity, which is often enlarged to a claviform widening. In the sections the appendages of the cuticle have assumed the same color as the cuticle itself.

The mantle-cavity (Pl. II, fig. 5) is large and contains a considerable number of developing eggs. The egg-tubes have not been sufficiently preserved in this specimen. Retinacula were not to be detected, neither in the wholly mounted preparations of portions of the mantle, nor in the longitudinal sections of the whole animal. The mantle-opening is contracted, it is surrounded by a strongly-developed sphincter. The mesentery is found from the peduncle to the mantle-opening, it is comparatively thin. Where it is attached to the peduncle the mesentery contains a large lacune. The peduncle is very short and highly muscular.

The visceral mass is surrounded by a sheath of transversal muscles. It is filled for the greater part by the ovary, which is crowdedly filled with eggs. Between the eggs a great number of muscular strains are found which connect the two lateral surfaces of the visceral mass. The colleteric glands are very regularly built. They form more or less round protrusions which project wholly at the sides of the visceral mass. They are therefore not, as in other species of Sacculina, imbedded in the viscera mass. The glands consist of a number of tubes the free extremities of which are neatly arranged in one row. These tubes unite to larger tubes with a more irregular course which are in connection 
with the visceral mass. Pl. II, fig. 5 represents a slightly oblique section. Here the larger (proximal) parts of the tubes of the left colleteric gland are found and the free extremities of the tubes of the right colleteric gland are visible.

Both the testes have approximately the same size and the same length. In the portion just before the beginning of the vas deferens the testis of the right side is slightly more developed than that of the left side. In the whole of their extent the testes are situated next to one another. The vasa deferentia are slightly twisted, the male genital openings are found at either side of the base of the peduncle in the ventral half of the visceral mass.

Sacculina pustulata $\mathrm{n} . \mathrm{sp}$.

(P1. II, figs. 2, 6 and 7 , text figs. 2 and 3).

Spanish Water, Curaçao, 5. V. 1920, 1 ex. on Hemus cristulipes A. Milne Edw. . .

The animal, which is attached with a short stalk to the abdomen of the crab, has a nearly circular, laterally compressed, form. Its greatest breadth is $3 \mathrm{~mm}$, the height $2 \frac{1}{2}$ and the greatest thickness (in the central part) slightly less than $2 \mathrm{~mm}$. The mantle-opening is situated at the extreme anterior margin. It lies at the top of a small papilla at either side of which a notch is found in the margin of the animal. Similar notches are present next to the stalk, so that the posterior margin projects with an ear-like protrusion at each side of the stalk. At the surface which is directed towards the abdomen of the crab a shallow groove is present which was lying on the surroundings of the gut of the crab. With a slight enlargement the parasite has a dotted appearance (Pl. II, fig. 2): the indentations in the mantle caused by pressure of the eggs in the mantle-cavity are visible by the transparency of the external cuticle.

The mantle consists of a thin muscular layer which shows the impressions of the eggs. It is covered by an $8-12 \mu$ thick external cuticle which has a structure of chitin parallel to that of the mantle. The upper surface of the external cuticle is divided into small round knobs which have all approximately the same size, their transverse diameter varying from 12 to $16 \mu$. These knobs are separated by small shallow grooves (fig. 2). On account of this structure the external surface of the mantle has a very neat appearance when it is strongly enlarged. It then presents a regular meshwork of the furrows between the knobs (fig. 3). In the

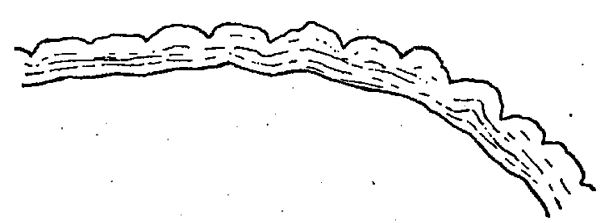

Fig. 2. Sacculina pustulata. Section of the external cuticle of the mantle. $\times 370$. longitudinal sections the external cuticle has separated from the

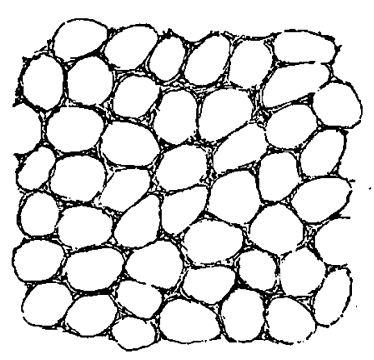
muscular layers of the mantle. By this process a large space has developed between the chitinous sheath of the mantle and the muscular part, which is as a matter of fact a quite artificial product.

The mantle-cavity (Pl. II, fig. 6) is large. It contains a great number of developing eggs which are for the greater part surrounded by the egg-tubes. I could not find the retinacula of this specimen in any of the sections and wholly mounted preparations. The mantle-opening is very narrow, it is surrounded by a strongly developed sphincter. In the remaining parts of the mantle the muscular

Fig. 3. Sacculina pustulata. tissue is very poorly developed in comparison with the portion in the neighExternal cuticle of the mantle, seen from above. $\times 370$. bourhood of the mantle-opening. The mesentery extends from the mantle-opening to the peduncle. In the latter portion it connects the visceral mass to the peduncle. Here a lacune is found in its central part. The peduncle is a little distorted from the remaining parts of the body, in the sections still its highly muscular condition is evident.

The visceral mass consists chiefly of the ovary, which is sheathed by a thin layer of muscles. The external surface of the visceral mass has obtained a number of indentations by the pressure of the eggs in the mantle-cavity against it. Between the eggs in the ovary hardly any muscular fibres are to be found. The colleteric glands are present at either side of the ovary. They are very thin and have as the ovary assumed a toothed external surface by the pressure of the eggs in the mantle-cavity. The glands contain a great number of tubes which unite and form the oviduct. Only in the part 
surrounding the oviduct (the proximal portion) the colleteric glands project slightly more in the mantle-cavity. In fig. 6 of Pl. II the proximal part of the right colleteric gland is visible and the distal part of the left, owing to the section being slightly oblique.

The testes are situated next to one another. They differ considerably in size, that of the right side is much larger than the left one. Pl. II, fig. 7 represents a part of a section in the region where the left testis attains its largest width. Besides its relative smallness it differs moreover from the right one by its much shorter length, in the region where the right testis attains its strongest development nothing at all is to be seen of the left testis (Pl. II, fig. 6). The vasa deferentia are short and curved tubes. The male genital openings are found in the ventral part of the body, each opening at one side of the visceral mass.

Sacculina tessellata $\mathrm{n} . \mathrm{sp}$.

(P1. II, figs. 3, 8, 9 and 10, text figs. 4 and 5).

Caracas Bay, Curaçao, 23. IV. 1920, 1 ex. on Mithrax ruber (Stimp.)

The shape of the parasite is cordiform, the short stalk, with which it is attached to the abdomen of its host, at the broad extremity. Its greatest breadth, height and thickness are respectively $4{ }_{1}^{1}, 4$ and $1 \frac{1}{4} \mathrm{~mm}$. The body possesses a longitudinal ridge at the surface which was directed towards the thorax of the crab, running from the stalk to the mantle-opening. At the other surface, which was lying against the abdomen of the crab, a deep furrow has developed owing to the pressure of the surroundings of the gut of the host on the parasite. The mantle-opening is comparatively wide; it lies at the top of a small papilla at the apex of the anterior pole, somewhat nearer to the thorax than to the abdomen of the crab.

The external surface of the mantle presents already with a slight enlargement a very ragged appearance. It shows a great many wart-like protrusions and has in many places a worn-off appearance. With a stronger power in the greater part of the external surface of the mantle a large number of small glittering excrescences are detected which are neatly arranged as a tessellated pavement (fig. 5). These excrescences have a diameter of 6 to $12 \mu$. They are very neatly united, leaving only shallow grooves between them. The excrescences are very clearly visible in a regularly arranged manner on the wart-like protrusions of the mantle. Next to these patches of glittering chitinous appendages there are other regions where these structures seem to be wanting. Sections of the mantle show that the external cuticle consists of chiefly two portions (fig. 4). The lower portion consists of parallel layers of chitin, which have a strong affinity to the colouring matter. This part has about the same thickness (12

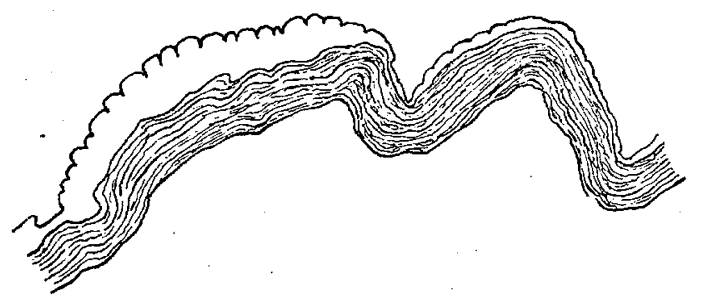

Fig. 4. Sacculina tessellata. Section of the external cuticle of the mantle. $\times 370$.

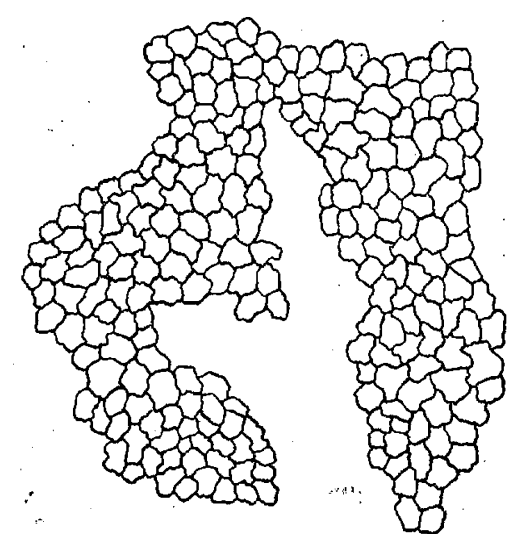

Fig. 5. Sacculina tessellata. External cuticle of the mantle, seen from above. $\times 370$.

to $16 \mu$ ) in all regions of the mantle. In many parts of the mantle only this lower, strongly coloured cuticular sheath is to be found. In other regions it is covered by another layer which takes no color at all nor shows the striations of the lower part of the cuticle. This higher layer is strongly refractive. Doubtless it consists of a quite different kind of chitin. Its thickness is very variable, in. some places it may attain $14 \mu$, in other places it is extremely thin or it seems to want completely. The free surface of this refractive part of the cuticle is divided into the small appendages which are shown in fig. 5. In the series of longitudinal sections the external highly refractive layer has been preserved only in very few places, in other parts of the mantle it is lost. Probably during the life of the paràsite 
every now and then fragments of this part of the cuticle loosen from the underlying portion, which may explain the somewhat ragged appearance of the external surface of the mantle.

Besides the cuticle the mantle (PI. II, fig. 8) consists of the usual muscular elements, between which a great many lacunes are present. The transvarsal muscles are strongly developed. The internal cuticle of the mantle has loosened from the muscular layers for the greater part of its extent. It is a very thin chitinous layer. The mantle-cavity is comparatively little and contains but few eggs. I have found neither the egg-tubes nor the retinacula in the preparations and in the sections of this specimen. The mantle-opening is surrounded by a strong sphincter. The mesentery, which extends from the mantle-opening to the peduncle, becomes much broader in the region of the latter. Here it is strongly muscular and a large lacune is found in the dorsal part of the broadened region (PI. II, fig. 9). The short peduncle also contains many muscles.

The external region of the visceral mass consists of a well-developed muscular layer. Only very few eggs are to be seen in the visceral mass, the ovary seems to be poorly developed. Between the eggs and in the other parts a great number of muscular strains traverse the visceral mass in all directions, though chiefly in the direction at right angles to the lateral surfaces. The colleteric glands (P1. II, fig. 10) consist in the usual way of a number of tubes.

The two testes are well-developed (Pl. II, fig. 8). Approximately they have the same size and the same length. One of the testes is situated for the greater part of its extent nearer to the mantleopening than the other (i. e. anterior to the other). The vasa deferentia have a slightly curved course, their extremities are found next to one another. The male genital openings are found one at either side of the visceral mass. The place of the male genital openings proves that the left testis is situated anterior to the right one.

\section{Lernaeodiscus bilobatus n. sp.}

(P1. II, figs. 4, 11 and 12).

Caracas Bay, Curaçao, 10. V. 1920, 1 ex. on Petrolisthes amoenus (Guérin) ㅇ.

The bilateral symmetrical, flattened body of the parasite possesses two lateral protrusions which project behind the peduncle. The greatest breadth, height (in the central part) and thickness are respectively $4 \frac{1}{2}, 2 \frac{1}{2}$ and $1 \frac{1}{4} \mathrm{~mm}$. The animal is attached to the abdomen of its host. The mantleopening lies at the top of a small papilla, which is directed towards the extremity of the abdomen of the host. Next to this papilla a pair of notches separate it from the neighbouring parts. The main axis of the parasite has the same direction as that of the host.

The mantle is comparatively thin, but strongly muscular. The epithelial and transversal muscular elements are well-developed and the inner layer of the mantle contains many lacunes. The external surface is covered by a thin (about $3 \mu$ thick) cuticle, which forms a thin chitinous sheath enveloping the animal (Pl. II, fig. 11). It was separated from the muscular layers probably by the contraction of the muscular elements. The mantle-cavity is extremely small, in the greater part of the body it is reduced to small slits between the visceral mass and the mantle. There are no eggs in the mantle-cavity. The mantle-opening is comparatively wide, the surrounding sphincter is only slightly developed.

The visceral mass is completely divided into two lateral parts by a strong muscular septum which also divides the dorsal part of the mantle-cavity into two halves. Here it is united with the mantle, forming in this way the mesentery. On one side the mesentery projects considerably farther towards the mantle-opening than at the other side. The surface with the longer part of the mesentery can therefore be called the right surface (cf. SMITH 1915). The visceral mass consists for the greater part of the ovary which is completely filled with eggs. Besides the median muscular septum there are two more of these septa, each in the middle of one of the two lateral halves. The dorsal parts of these septa traverse the whole body and constitute thereby also a kind of mesentery (Pl. II, fig. 11). They are, however, much shorter than the mesial mesentery and do not divide the two halves of the ovary into completely separated portions.

The colleteric glands have a roundish shape. They are flattened in the direction of the chief axis of the animal and contain a system of branched tubes. One lies in the posterior half of the body 
and is imbedded in the left surface of the ovary. The other, which is imbedded in the right surface of the ovary, is situated before the large mesial mesentery.

The testes are found in the dorsal, broader part of the large mesentery, in the neighbourhood of the stalk. Each of these consists of a slightly curved tube, which gradually diminishes in width and passes into the vas deferens. Both vasa deferentia open backwards in the same half of the mantlecavity (Pl. II, fig. 12).

\section{LITERA T URE.}

Y. Delage (1884). Évolution de la Sacculine. Arch. de Zool. Exp. et Gén. (2), T. II.

A. GIARD (1887). La castration parasitaire et son influence sur les caractères extérieurs du sexe male chez les Crustacés Décapodes. Bull. Scient. du Nord de la France et de la Belgique (2), $10^{\mathrm{me}}$ année (T. XVIII).

(1888). Le Laboratoire de Wimereux en 1888. (Recherches fauniques). Bull. Scient. de la France et de la Belgique (3), Vol. I (T. XIX).

J. GUÉRIN-Ganivet (1911), Contribution à l'étude systématique et biologique des Rhizocéphales. Trav. Sc. du Lab. de Zool. et de Physiol. maritimes de Concarneau, T. III.

P. N. VAN KAMPen (1919). Over de Rhizocephalen der Siboga-Expeditie. Tijdschr. d. Ned. Dierk. Ver. 2e serie, Deel XVIII, Verslagen.

R. Kossmann (1874). Beiträge zur Anatomie der schmarotzenden Rankenfüssler. Arb. zool.-zoot. Inst. Würzburg. Bd. I. G. SмIтH (1906). Rhizocephala. Fauna und Flora des Golfes von Neapel.

- (1915). The Genus Lernaeodiscus (F. Müller, 1862). Journ. Linn. Soc. London, Zool., Vol. XXXII.

\section{EXPLANATION OF THE PLATE.}

The figs. 1-4 are photographs of the surface of the parasites which was directed towards the thorax of the host. The mantle-opening is found at the upper part of the figure.

The abbreviations used in all other figures are as follows:

$c$ external cuticle of the mantle.

$e$ developing eggs in the mantle-cavity.

et egg-tubes.

$i c$ internal cuticle of the mantle.

$l c g$ colleteric gland of left side.

$l t$ testis of left side.

$l v d$ vas deferens of left side.

$m$ mantle.

$m c$ mantle-cavity.

mes mesentery. mo mantle-opening.

$o$ ovary.

$p$ peduncle.

$r c g$ colleteric gland of right side.

$r t$ testis of right side.

$s$ muscular septum, forming a kind of accessory mesentery.

$s p h$ sphincter.

$v m$ visceral mass.

Fig. 1. Sacculina hirsuta. $\times 5$.

Fig. 2. Sacculina pustulata. $\times 5$.

Fig. 3. Sacculina tessellata. $\times 5$

Fig. 4. Lernaeodiscus bilobatus. $\times 5$. One half is slightly damaged, here a portion was cut off for the study of the external structure of the mantle.

Fig. 5. Sacculina hirsuta. Longitudinal section. $\times 45$. The dotted lines indicate the portion of the mantle which has been cut off.

Fig. 6. Sacculina pustulata. Longitudinal section. $\times 45$

Fig. 7. Sacculina pustulata. A part of a longitudinal section in the region of the left vas deferens. $X 45$.

Fig. 8. Sacculina tessellata. Longitudinal section. $\times 45$.

Fig. 9. Sacculina tessellata. Longitudinal section of the visceral mass in the region of the strongest development of the ovary. $\times 45$.

Fig. 10. Sacculina tessellata. A part of a longitudinal section through the visceral mass showing the colleteric gland of the right side. $\times 45$.

Fig. 11. Lernaeodiscus bilobatus. Transversal section. $\times 45$.

Fig. 12. Lernaeodiscus bilobatus. The central part of a transversal section in the region of the male genital openings. $\times 45$. 

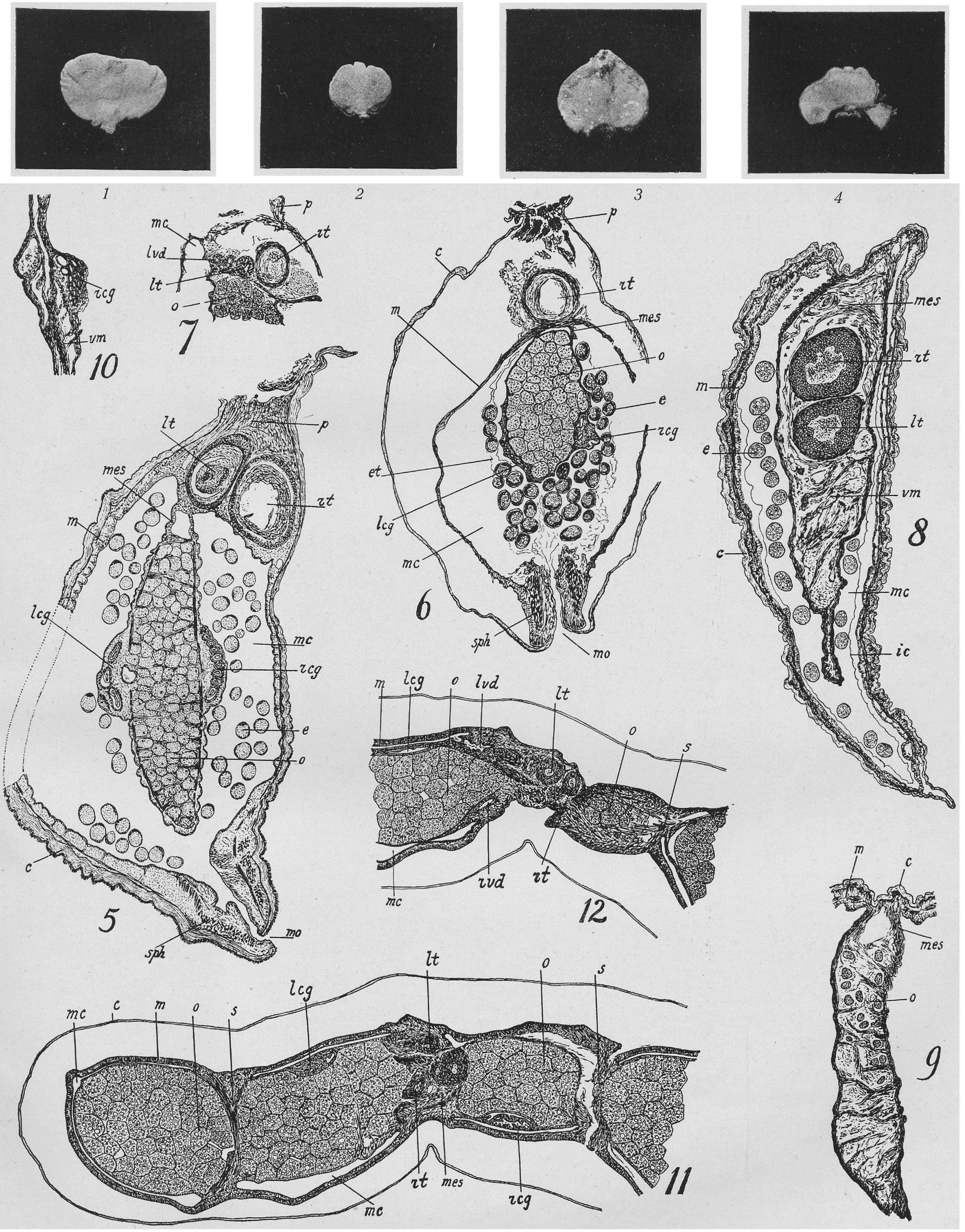